\title{
Fusarium concolor X4 Pretreatment Suppresses Light-Induced Yellowing of High-Yield Pulp
}

\author{
Daolei Zhang $\mathbb{D}^{1,2}$ Xuezhi Li ${ }^{1},{ }^{1}$ and Jian Zhao $\mathbb{D}^{1}$ \\ ${ }^{1}$ State Key Laboratory of Microbial Technology, Shandong University, Qingdao 266237, China \\ ${ }^{2}$ Department of Bioengineering, Shandong Polytechnic, Jinan 250104, China \\ Correspondence should be addressed to Xuezhi Li; lixz@sdu.edu.cn and Jian Zhao; zhaojian@sdu.edu.cn
}

Received 16 November 2019; Accepted 8 January 2020; Published 1 February 2020

Academic Editor: Ali Nokhodchi

Copyright ( 2020 Daolei Zhang et al. This is an open access article distributed under the Creative Commons Attribution License, which permits unrestricted use, distribution, and reproduction in any medium, provided the original work is properly cited.

High-yield pulps (HYPs), such as CTMP (chemi-thermo-mechanical pulp), are attractive due to their low cost and high wood utilization. However, their drawback of rapid brightness reversion (yellowing) limits wide use of the HYPs. In this study, a fungus, Fusarium concolor X4, was applied to treat poplar CTMP for exploring the effects of biotreatment on brightness and light-induced yellowing of the pulp. The results indicated that the biotreatment with Fusarium concolor X4 could improve the brightness of poplar CTMP and inhibit light-induced yellowing of the pulp. The yellowing inhibition mechanism was explored by the analysis of enzyme production regularity during biotreatment, changes in chemical components, and the UV-Vis absorption spectra and FTIR-ATR spectra of pulps before and after biotreatment.

\section{Introduction}

The increasing forest resource consumption and environmental pollution are the two most serious problems for the pulp and paper industry. Researchers have done intensive studies for these problems [1]. Efficient utilization of forest resources in paper industry is important for both industry and society $[2,3]$. Compared with chemical pulps such as kraft pulp, HYPs, with their high utilization efficiency of wood, are a dramatic way to resolve the problems of wood shortages and higher capital costs. In addition, HYPs can also give fine papers with higher stiffness, bulk, and opacity and better printability [4].

However, the well-known "brightness reversion (also called yellowing)" of HYPs is a major drawback in HYPs application [5]. Generally, pulp yellowing includes light- and heat-induced yellowing. For HYPs, because of the high lignin content, light is the main cause for yellowing. The lignin-based reactions, which include the phenoxyl pathway, the ketyl pathway, the phenacyl pathway, and the phenoxyl quinone redox cycle $[6,7]$, could produce quinones and some other UV-active substances, leading to pulp brightness reversion. Besides, the hexenuronic acid (HexA), low molecular organic compounds, and metal ions in pulp could also cause pulp brightness reversion [8].

According to previous researches, there are many methods to suppress the pulp yellowing. For example, UV absorbers are efficient substances to prevent brightness reversion. It had been reported that thiols or sodium hypophosphite were effective for preventing the light-induced yellowing [9, 10]. 1-oxyl-2,2,6,6-tetramethylpiperidin-4-ol, an inhibitor, was found that could help maintain paper brightness for at least one year [11]. Fluorescent whitening agents (FWAs), chemical modification, and paper coating are also effective methods that can be applied to slow down pulp yellowing. Although these methods could retard yellowing of HYPs, high cost and toxicity of some chemicals limit their industrial application; on the other hand, they will only temporarily delay the yellowing [5].

In recent years, biotreatment is increasingly applied for pulping and bleaching processes in pulp industry because of its environmental friendliness and low cost. Many researchers had done lots of works in this field [12-14]. For example, E. grandis wood was treated with fungus C. subvermispora to produce bleached bioTMP (thermomechanical pulp) and found the bleached biotreated pulp had better 
thermal-stability than the control, while the photo-stability was similar for both pulps [15]. Microorganisms especially white rot funguses are rich in enzymes for degradation of lignin and hemicellulose, such as xylanase, laccase, $\mathrm{MnP}$, LiP, etc. $[16,17]$. These enzymes can degrade chromophores of pulp and its precursors, which are well beneficial to inhibit pulp yellowing $[15,18,19]$. Besides, the biotreatment could make pulps easier to be bleached and refined, thus decrease the consumption of bleaching agents and save considerable electrical energy, and the pulp strengths of burst, tear, and tensile were also improved [18].

Fusarium concolor $\mathrm{X} 4$ (F. concolor $\mathrm{X} 4)$ is a fungus that has efficient delignification ability, which was screened and preserved in our laboratory. Our previous studies showed treatment with $F$. concolor $\mathrm{X} 4$ could effectively improve brightness and inhibit heat-induced yellowing of unbleached poplar CTMP and wheat straw semichemical pulp [20-22]. In this paper, we studied the effect of $F$. concolor X4 pretreatment on light-induced yellowing of poplar CTMP, and the mechanism of yellowing inhibition was studied by investigating the changes on different types of enzymes produced by the strain and on chemical components of pulps, the UV-Vis absorption spectra, and FTIR-ATR spectra before and after the biotreatment.

\section{Materials and Methods}

2.1. Pulps. Unbleached Poplar CTMP was kindly provided by Hua tai Paper Co., Ltd. (Shandong, China). The pulp was washed twice with tap water and preserved at $4^{\circ} \mathrm{C}$.

2.2. Microorganism. F. concolor $\mathrm{X} 4$ was screened from decayed wood and maintained on PDA slants in our laboratory [20].

2.3. Precultivation. The media $(80 \mathrm{~mL})$ contained $20 \mathrm{~g} / \mathrm{L}$ glucose, and $5 \mathrm{~g} / \mathrm{L}$ yeast extracted powder was used for precultivation of $F$. concolor $\mathrm{X} 4$. The strain was grown for about 3 days at $28^{\circ} \mathrm{C}$ at $150 \mathrm{rpm}$ to inoculate the shake flask until the cell concentration reached $10^{8}$ Colony-Forming Units per $1 \mathrm{~mL}(\mathrm{CFU} / \mathrm{mL})$.

\subsection{Biotreatment of Pulp with F. concolor X4 and Sampling.} Poplar CTMP (40 g oven dry weight) were adjusted to $5 \%$ consistency with solution $\left(\mathrm{NH}_{4} \mathrm{Cl} 0.2 \mathrm{~g}, \mathrm{MgSO}_{4} \cdot 7 \mathrm{H}_{2} \mathrm{O} 0.5 \mathrm{~g}\right.$, $\mathrm{KH}_{2} \mathrm{PO}_{4} 0.2 \mathrm{~g}, \mathrm{Na}_{2} \mathrm{HPO}_{4} 0.2 \mathrm{~g}, \mathrm{FeSO}_{4} \cdot 7 \mathrm{H}_{2} \mathrm{O} 0.007 \mathrm{~g}, \mathrm{MnSO}_{4}$ $0.035 \mathrm{~g}, \mathrm{CuSO}_{4} \cdot 5 \mathrm{H}_{2} \mathrm{O} 0.007 \mathrm{~g}$ dissolved in $1 \mathrm{~L}$ of distilled water) in flasks ( $3 \mathrm{~L}$ ) and autoclaved at $115^{\circ} \mathrm{C}$ for $30 \mathrm{~min}$. After cooling down to room temperature, the homogenized pregrown culture $(5 \%, \mathrm{~V} / \mathrm{V})$ was inoculated into the flasks. The pulps were incubated at $28^{\circ} \mathrm{C}$ for up to 10 days in an oscillation incubator with shaking at $150 \mathrm{rpm}$. The samples inoculated with inactivated pregrown culture by sterilization were used as control. For each sample, three replicates were made.

Pulp slurry was sampled by sampling spoon at selected times $(2,4,6,8,10$ days). Flasks were shaken as far as possible to make the matrix evenly before sampling, and $2 \mathrm{~g}$ of pulp (oven dry weight) was taken out for each flask. The pulp slurry sampled were collected by centrifugation at $4^{\circ} \mathrm{C}$ at $8000 \mathrm{rpm}$ for $10 \mathrm{~min}$ and then were washed twice in nylon cloth bags with $100 \mathrm{ml}$ water for further experiments. The supernatants obtained by centrifugation were collected for the determination of enzymes activities.

2.5. Pulp Bleaching. Biotreated pulps and the control were adjusted to $10 \%$ consistency, with $\mathrm{pH} 3.0$ in polyethylene bags, and firstly treated with $0.5 \%$ EDTA at $80^{\circ} \mathrm{C}$ in water bath for $30 \mathrm{~min}$ and then were bleached under the conditions of pulp consistency $10 \%, 80^{\circ} \mathrm{C}, \mathrm{NaOH} 1.5 \%, \mathrm{Na}_{2} \mathrm{SiO}_{3} 3 \%$, $\mathrm{MgSO}_{4} 0.5 \%$, and $\mathrm{H}_{2} \mathrm{O}_{2} 3 \%$ and $\mathrm{pH}$ of 10 to 11 for $2 \mathrm{~h}$. After EDTA treatment and bleaching, the pulps were thoroughly washed to neutral with distilled water. The $\mathrm{pH}$ of pulp was adjusted by using $\mathrm{H}_{2} \mathrm{SO}_{4} 2 \mathrm{~mol} / \mathrm{L}$ and $\mathrm{NaOH} 1 \mathrm{~mol} / \mathrm{L}$. After bleaching, the test sheets were prepared using the bleached pulps by a Buchner funnel containing a cloth, compressed between filter papers, and dried at room temperature $\left(25-27^{\circ} \mathrm{C}\right)$ in a dark environment.

2.6. Pulp Yellowing. Four UVB-340 lamps (20 Watts, Xue Laite, China), which emit UV-Vis light with wavelength $(\lambda)$ of 295-350 nm, and $\lambda_{\max }=340 \mathrm{~nm}$, were used for light-induced yellowing. The light intensities at the sample site were kept at $4.6 \mu \mathrm{W} / \mathrm{cm}^{2}$, which were determined by an ultraviolet irradiation meter. Temperatures in the aging box were kept at about $27^{\circ} \mathrm{C}$ by a cooling fan equipped in the box to minimize the heating effect of the light source. After $24 \mathrm{~h}$ irradiation, samples were conditioned in dark room for $4 \mathrm{~h}$ before analysis.

2.7. Enzyme Assays. Xylanase activity was determined by mixing $1.5 \mathrm{~mL}(1 \%, \mathrm{w} / \mathrm{v})$ of beech xylan solution prepared in $50 \mathrm{mM}$ NaAc-HAc buffer of $\mathrm{pH} 4.8$, and $0.5 \mathrm{~mL}$ of diluted enzyme, which was incubated at $50^{\circ} \mathrm{C}$ for $30 \mathrm{~min}$. The reaction was stopped by adding $3 \mathrm{ml} 3,5$-dinitrosalicylic acid (DNS) reagent and boiled for $10 \mathrm{~min}$ [23]. $\beta$-xylosidase activity was determined in buffer (NaAc-HAc, $\mathrm{pH} 4.8$, $50 \mathrm{mM}$ ) with $1 \mathrm{mM}$ 4-Nitrophenyl beta-D-xylopyranoside (pNPX) and suitable amount enzyme (total volume of $1.0 \mathrm{~mL}$ ) and incubated for $10 \mathrm{~min}$ at $45^{\circ} \mathrm{C}$. The reaction was stopped by $0.5 \mathrm{~mL}$ of $\mathrm{Na}_{2} \mathrm{CO}_{3}(1 \mathrm{M})$. The released p-nitrophenol (pNP) was determined at $420 \mathrm{~nm}$ [24]. Carboxymethyl-cellulase (CMCase) activity and filter paper activity (FPA) were measured using the DNS method according to the literature [25]. One unit of enzyme activity was defined as the amount of enzyme that liberates $1 \mu \mathrm{mol}$ of sugar (or pNP) equivalents per minute under the assay conditions.

Laccase activity was determined by determining the rate of oxidation of 2,2'-Azinobis-(3-ethylbenzthiazoline-6-sulphonate) (ABTS) [26]. LiP and MnP activities were determined according to the method described in the literature [27].

2.8. Pulp Brightness and Post Color Number. ISO brightness of pulp samples were determined by brightness color tester 
(YQ-Z-48A, Hangzhou light instrument development Co., Ltd., China). The degree of brightness reversion was expressed by post color number (PCN), which is calculated as follows:

$$
\mathrm{PCN}=100\left\{\left[\frac{\left(1-R_{\infty}\right)^{2}}{2 R_{\infty}}\right]_{\mathrm{after}}-\left[\frac{\left(1-R_{\infty}\right)^{2}}{2 R_{\infty}}\right]_{\text {before }}\right\},
$$

where $R$ denotes ISO brightness of a thick pad at $\lambda=475 \mathrm{~nm}$ [28].

2.9. Ultraviolet-Visible Diffuse Reflectance (UV-Vis DR) Spectra. UV-Vis DR spectra of pulp samples were recorded on a UV-2550 spectrometer (Shimadzu, Japan) equipped with an ISR-2200 integrating sphere, with $\mathrm{BaSO}_{4}$ as a background reference. The reflectance spectra were converted to $K / S$ values according to the Kubelka-Munk equation [29]. Difference UV-Vis absorption spectra $(\nabla K / S$ vs. wavelength) were obtained by subtracting the reflectance spectrum (K/S vs. wavelength) of control sample (un-irradiated sheet from that of the aged sheet. The $K$ and $S$ are the absorption and scattering coefficients. When the handsheets are thicker than $30 \mathrm{~g} / \mathrm{m}^{2}$, the change of S (scattering coefficient) value was very small, and it could be considered as constant [30]. In this case, $K / S$ value was directly related to the amounts of chromophores and UV-active substances in the hand-sheet [5]. And $\nabla K / S$ was approximately linear to the changes in chromophores or UV-active substances, which can be assumed according to the Kubelka-Munk theory.

2.10. Chemical Composition Analysis. Chemical compositions of pulps include the contents of acid-soluble lignin (ASL), acid-insoluble lignin (AIL), cellulose, and hemicellulose, were measured according to National Renewable Energy Laboratory (NREL, USA) analytical methods [31]. Hexeneuronic acid (HexA) content in pulp was measured by $\mathrm{UV}$-spectroscopy method described in the literature [32].

2.11. FTIR-ATR Difference Spectra. Fourier transform infrared-attenuated total reflectance (FTIR-ATR) spectra of pulps sheets were recorded with a Tensor 27 spectrophotometer (Brüker, Germany) [33]. The infrared difference spectra were obtained by spectra of pulp samples treated with F. concolor X4 minus that of samples without biotreatment (control).

2.12. Statistical Analysis. All of the FTIR-ATR spectra and UV-Vis DR spectra were representative of three independent experiments. The assays of pulp brightness, enzymes activities, and chemical components were performed in triplicate, and each experiment was repeated at least three times. The mean value and standard deviations were calculated using Microsoft Office 2010 Excell (Microsoft, USA). The differences were considered statistically significant at $P<0.05$ determined by using $t$-Student one-tail test.

\section{Results}

3.1. Effects of F. concolor X4 Treatment on Pulp Brightness and Brightness Stability. The pulp brightness of biotreated pulps and the control before and after light-induced yellowing are shown in Figure 1. It was found that the brightness of biotreated pulp samples was higher than that of the controls, either before or after light-induced yellowing, indicated that the F. concolor X4 treatment could improve pulp brightness. For example, the brightness of the biotreated pulp, respectively, increased by $5.0 \%$ and $12.2 \%(P<0.01, n=3)$ compared to the control after 2 and 6 days of $F$. concolor X4 treatment before light-induced yellowing. Subsequently, the increase of biotreated pulp brightness decreased, and only $3.7 \%(P<0.01, n=3)$ increased compared to the control after 8 days of treatment.

After light-induced yellowing, the increases on pulp brightness were $5.9 \%, 11.4 \%$, and $1.6 \%(P<0.01, n=3)$ for pulps obtained in 2nd day, 6th day, and 8th day treatment with F. concolor X4 compared to the control, respectively.

PCN is an index that expresses the pulps brightness reversion before and after yellowing. Figure 2 shows the PCNs of poplar CTMPs biotreated for different times and controls after light-induced yellowing. Compared with the control, the PCNs of all the pulps treated with F. concolor X4 were decreased. For example, the PCN value decreased by $12.0 \%$ after 2 days of biotreatment compared to the control and by $10.9 \%, 15.8 \%, 12.0 \%$, and $11.6 \%$ after treatment for 4 days, 6 days, 8 days, and 10 days, respectively.

During pulp treatment with $F$. concolor X4, samples obtained at different treatment time were centrifuged and different enzymes activities of the supernatant were detected (Table 1). It was found that LiP, xylanase, and cellulase appeared earlier, in which, the activities of LiP and xylanase reached $17.4 \mathrm{IU} / \mathrm{L}$ and $0.32 \mathrm{IU} / \mathrm{mL}(P<0.05, n=3)$ after treatment of 2 days. The MnP activity was $15.2 \mathrm{IU} / \mathrm{L}$ $(P<0.05, n=3)$ at the 4 th day of biotreatment. After 6 days treatment, laccase activity was detected (1 IU/L), and reached $1.2 \mathrm{IU} / \mathrm{L}$ at the 8 th day. $\mathrm{MnP}$ and $\mathrm{LiP}$ activities peak appeared at the 10th and 8th day, and reached $29.8 \mathrm{IU} / \mathrm{mL}$ and $23.4 \mathrm{IU} / \mathrm{L}(P<0.05, n=3)$ respectively. The activities of CMCase and $\beta$-xylosidase were almost not detected during entry treatment period.

3.2. UV-Vis DR Spectra of Pulps. Figure 3 shows the UV-Vis DR spectra $(\nabla K / S)$ of biotreated pulps and control before and after light-induced yellowing. The pronounced signal peaks appeared at around $340 \mathrm{~nm}$. And the strengths of signals at around $240 \mathrm{~nm}$ and $280 \mathrm{~nm}$ for controls were higher than that of biotreated pulps. For the biotreated pulp, the $\nabla K / S$ values were lower than that of control, especially for the pulps obtained by biotreatment of 6 days (Figure 3(b)).

The chemical components of poplar CTMP before and after biotreatment of $F$. concolor X4 were determined and are listed in Table 2. It was found that compared to the control, the contents of lignin and hemicellulose of the biotreated pulps were decreased by $1.7 \%$ and $8.4 \%(P<0.05, n=4)$, 


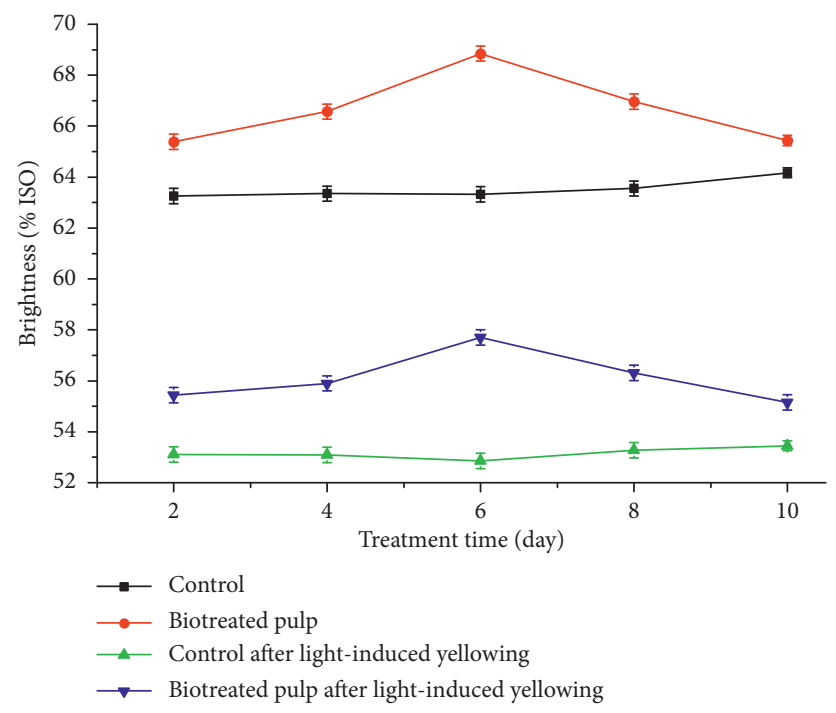

Figure 1: Effect of F. concolor X4 treatment on brightness of poplar CTMP before and after light-induced yellowing.

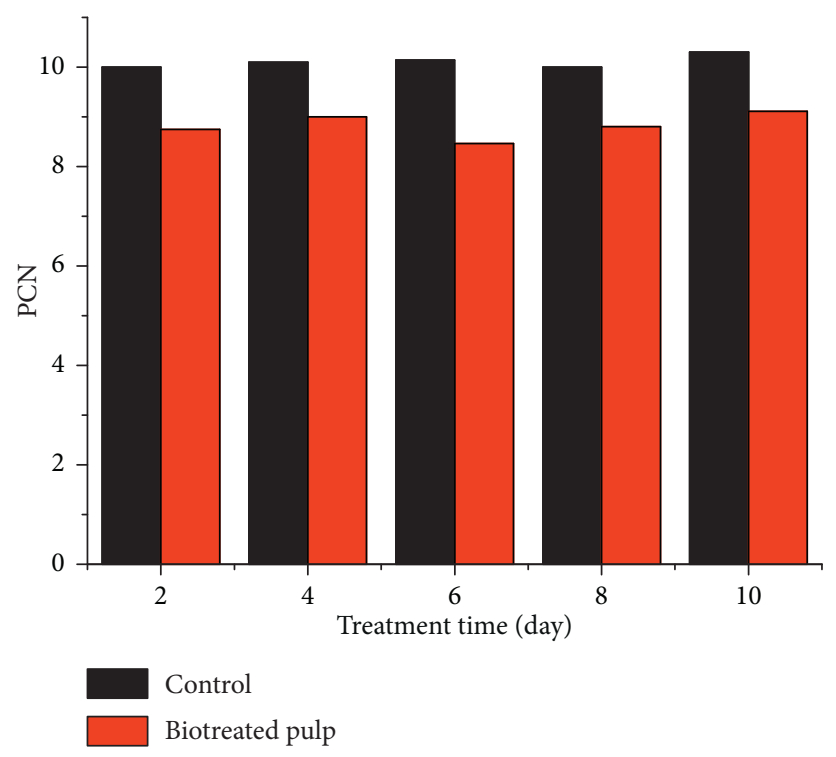

FIgURE 2: Changes of PCN of poplar CTMPs after treatment using F. concolor X4 for different times.

TABLE 1: The activities of enzymes produced by F. concolor X4 in poplar CTMP slurries during biotreatment.

\begin{tabular}{lccccccc}
\hline \multirow{2}{*}{ Treatment time (day) } & \multicolumn{5}{c}{ Enzyme activities } \\
& Lip (IU/L) & MnP (IU/L) & $\begin{array}{c}\text { Laccase } \\
(\mathrm{IU} / \mathrm{L})\end{array}$ & CMCase (IU/ml) & FPA (IU/ml) & $\beta$-xylosidase (IU/ml) & Xylanase (IU/ml) \\
\hline 2 & $17.4 \pm 2.4$ & Trace & Trace & Trace & $0.01 \pm 0.005$ & Trace & $0.32 \pm 0.05$ \\
4 & $19.6 \pm 3.2$ & $15.2 \pm 3.1$ & Trace & Trace & $0.01 \pm 0.005$ & Trace & $0.23 \pm 0.05$ \\
6 & $21.0 \pm 3.4$ & $13.1 \pm 2.4$ & $1.0 \pm 0.6$ & Trace & $0.01 \pm 0.005$ & Trace & $0.23 \pm 0.05$ \\
8 & $23.4 \pm 2.8$ & $10.5 \pm 3.4$ & $1.2 \pm 0.4$ & Trace & $0.01 \pm 0.005$ & Trace & $0.09 \pm 0.05$ \\
10 & $20.1 \pm 2.8$ & $29.8 \pm 3.1$ & $0.6 \pm 0.2$ & Trace & $0.01 \pm 0.005$ & Trace & $0.05 \pm 0.01$ \\
\hline
\end{tabular}

Data represent mean $\pm \mathrm{SD}, n=3$ 


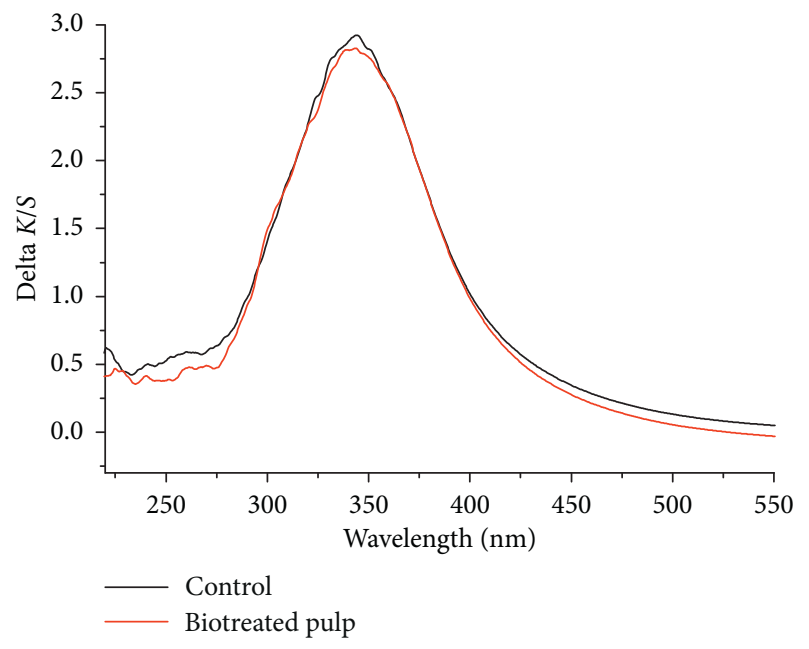

(a)

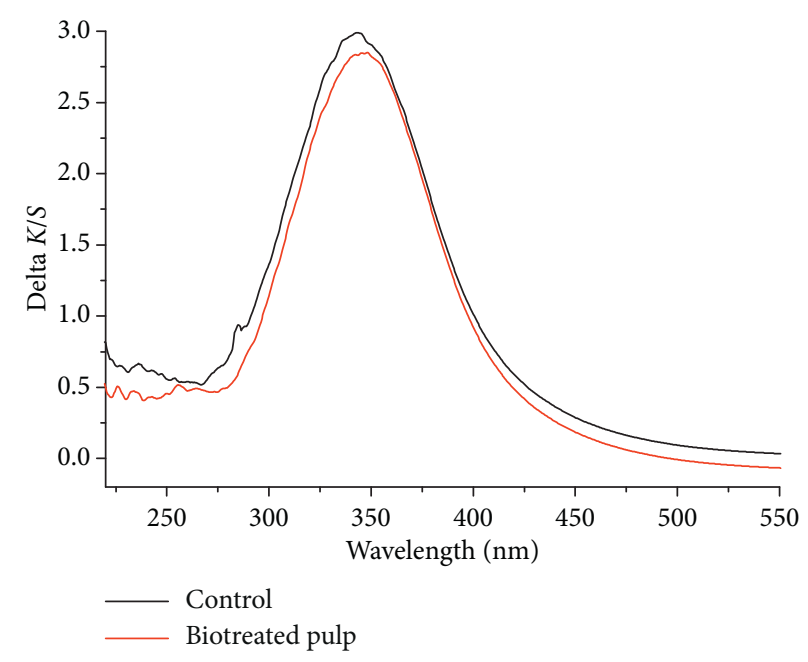

(b)

Figure 3: Difference UV-Vis absorption $(\nabla K / S)$ spectra of poplar CTMP before and after treatment of 2 days (a) and 6 days (b), respectively, using F. concolor X4.

TABLe 2: Chemical components of poplar CTMP before and after treatment using F. concolor X4 at different treatment times.

\begin{tabular}{lcccccc}
\hline Pulps & & Lignin $(\%)$ & Cellulose $(\%)$ & Hemicellulose $(\%)$ & HexA $(\mu$ mol/g) & Others $(\%)$ \\
\hline \multirow{2}{*}{2 day } & Control & $35.5 \pm 0.6$ & $44.5 \pm 0.3$ & $14.3 \pm 0.4$ & $4.4 \pm 0.4$ & 5.7 \\
& Biotreated pulp & $34.9 \pm 0.3$ & $46.1 \pm 0.2$ & $13.1 \pm 0.2$ & $4.1 \pm 0.3$ & 5.9 \\
\hline \multirow{2}{*}{6 day } & Control & $35.1 \pm 0.3$ & $44.1 \pm 0.3$ & $14.3 \pm 0.1$ & $4.7 \pm 0.4$ & 6.5 \\
& Biotreated pulp & $34.0 \pm 0.3$ & $46.9 \pm 0.2$ & $12.5 \pm 0.2$ & $2.9 \pm 0.4$ & 6.6 \\
\hline
\end{tabular}

Data represent mean $\pm \mathrm{SD}, n=3$.

respectively, after 2 days treatment of $F$. concolor $\mathrm{X} 4$, and by $3.1 \%$ and $12.6 \%(P<0.05, n=4)$, respectively, after 6 days of biotreatment. The HexA contents were also decreased by biotreatment. For example, decreased by about $6.8 \%$ $(P<0.05, n=4)$ at the 2 th day and $38.3 \%(P<0.05, n=4)$ at the 6 th day, respectively.

3.3. FTIR-ATR Spectrum Analysis. FTIR-ATR spectra of poplar CTMP and control before and after treatment of 2 days and 6 days with F. concolor X4 are shown in Figure 4. Table 3 shows some main absorption bands and their relative intensities [33-35].

It was indicated by the FTIR-ATR spectra that the intensities of certain bands were changed after biotreatment compared to the control. The absorptions at $896-897 \mathrm{~cm}^{-1}$ related to vibrations of anomeric carbon $\left(C_{1}\right)$ in hemicellulose, and the absorptions at $1160 \mathrm{~cm}^{-1}, 1103-1108 \mathrm{~cm}^{-1}$, and $1052-1053 \mathrm{~cm}^{-1}$ which related to vibrations of C-O-C, $\mathrm{O}-\mathrm{H}$, and $\mathrm{C}-\mathrm{O}$ bands, respectively, in cellulose and hemicellulose were decreased. Absorption at $1031 \mathrm{~cm}^{-1}$ related to hemicellulose or $\mathrm{G}$ type lignin vibrations and absorption at $1231 \mathrm{~cm}^{-1}$ related to $\mathrm{C}-\mathrm{O}$ (syringyl) bending vibrations were also decreased compared to the control (Table 3).

\section{Discussion}

The different types of enzymes, include cellulase, xylanase, $\mathrm{MnP}$, LiP, and laccase, could be produced during

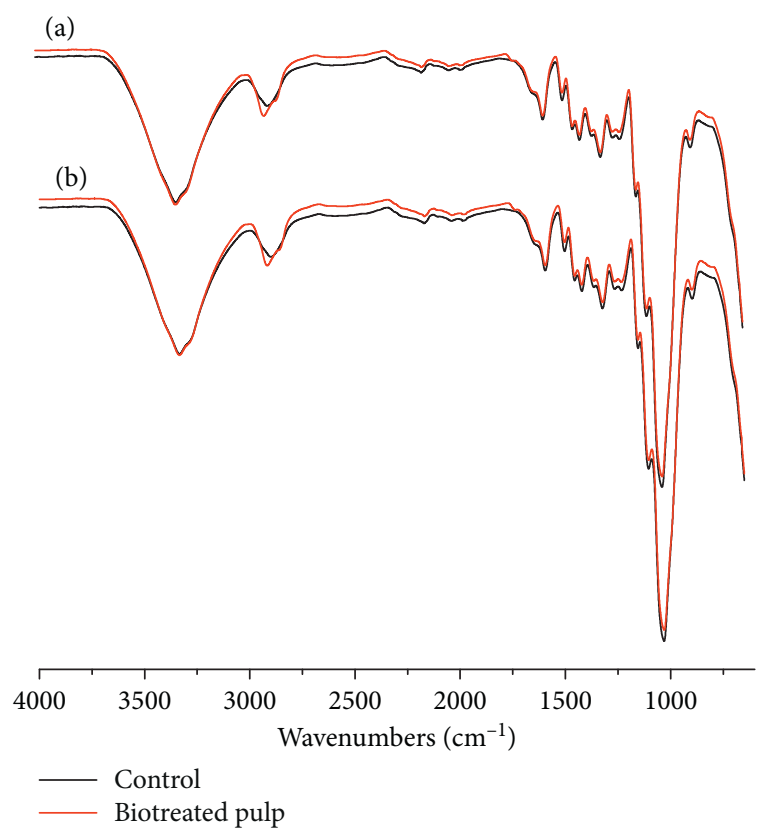

FIGURE 4: FTIR-ATR spectra of poplar CTMP before and after treatment of 2 days (a) and 6 days (b), respectively, using F. concolor $\mathrm{X} 4$.

biotreatment of poplar CTMP with F. concolor X4 (Table 1). The enzymes could degrade hemicellulose, HexA, and lignin in the pulp, which was confirmed by analyzing changes in 
TABLE 3: Signal assignment in FTIR-ATR spectra of poplar CTMP and changes in spectra intensity before and after treatment of 2 days and 6 days using F. concolor X4.

\begin{tabular}{|c|c|c|c|c|c|}
\hline \multirow{3}{*}{ Wavenumber $\left(\mathrm{cm}^{-1}\right)$} & \multirow{3}{*}{ Band assignment } & \multicolumn{4}{|c|}{ Relative intensity $^{\mathrm{a}}$} \\
\hline & & \multicolumn{2}{|c|}{2 days } & \multicolumn{2}{|c|}{6 days } \\
\hline & & Control & Sample & Control & Sample \\
\hline $3333-3336$ & $\mathrm{O}-\mathrm{H}$ (-OH groups) stretching vibrations & 1.37 & 1.50 & 1.37 & 1.53 \\
\hline $2896-2899$ & $\mathrm{C}-\mathrm{H}\left(-\mathrm{CH}_{2-}^{-},-\mathrm{CH}_{3}\right)$ stretching vibrations & 0.62 & 0.64 & 0.62 & 0.65 \\
\hline 1593 & Aromatic skeletal stretching vibrations & 0.81 & 0.84 & 0.82 & 0.87 \\
\hline 1503 & Aromatic skeletal stretching vibrations & 0.70 & 0.73 & 0.71 & 0.73 \\
\hline 1459 & $\mathrm{C}-\mathrm{H}$ - deformation; $-\mathrm{CH}_{3}$ and $-\mathrm{CH}_{2}-$ asymmetric vibrations & 0.86 & 0.89 & 0.89 & 0.90 \\
\hline $1422-1429$ & Aromatic skeletal vibrations & 1 & 1 & 1 & 1 \\
\hline $1315-1317$ & $\mathrm{CH}_{2}$ vibrations in cellulose and hemicellulose & 1.09 & 1.08 & 1.10 & 1.06 \\
\hline $1204-1231$ & C-O (syringyl) bending vibrations & 1.06 & 0.99 & 1.03 & 0.96 \\
\hline 1160 & $\mathrm{C}-\mathrm{O}-\mathrm{C}$ stretching in cellulose and hemicellulose & 1.61 & 1.54 & 1.51 & 1.44 \\
\hline $1103-1108$ & $\mathrm{O}-\mathrm{H}$ association band in cellulose and hemicellulose & 2.61 & 2.58 & 2.60 & 2.53 \\
\hline $1052-1053$ & $\mathrm{C}-\mathrm{O}$ stretching vibrations in cellulose and hemicelluloses & 5.22 & 4.97 & 5.20 & 4.86 \\
\hline $1030-1031$ & Hemicellulose or $\mathrm{G}$ lignin vibrations & 6.25 & 5.90 & 6.23 & 5.63 \\
\hline $896-897$ & Anomeric carbon $(\mathrm{C} 1)$ vibrations in hemicellulose & 1.19 & 1.03 & 1.21 & 1.03 \\
\hline
\end{tabular}

${ }^{a}$ Relative intensity was the ratio of the intensity of a given band to the intensity of the reference band at $1422-1429 \mathrm{~cm}^{-1}$.

chemical components of the pulps before and after biotreatment (Table 2). It was known that hemicellulose, HexA, and lignin are light-sensitive and easy to be light-degraded to produce chromophores $[36,37]$, thus leading to light-induced yellowing of pulp. The brightness improvement of poplar CTMP treated with F. concolor X4 should be due to the degradation of hemicellulose, HexA, and lignin. The decrease in pulps brightness after 6 days of biotreatment may be due to the production of new chromophores from enzymatic degradation of lignin and repolymerization of degraded products of lignin [20]. For example, it has been reported that laccase has a role in the polymerization of lignin $[38,39]$.

Lower $\nabla K / S$ values (Figure 3) of biotreated pulps, compared to the control, indicate that biotreatment reduced the production of light absorbing substance (including chromophores and their precursors etc.). This is consistent with the changes in the pulp brightness (Figure 1) and PCN values (Figure 2). This may be mainly related to the degradation of lignin caused by lignin-degrading enzymes such as $\mathrm{LiP}, \mathrm{MnP}$, and laccase $[40,41]$ detected in pulp during biotreatment. The decrease of signal $(\nabla \mathrm{K} / \mathrm{S})$ at $240 \mathrm{~nm}$ and $280 \mathrm{~nm}$ after biotreatment (Figure 3) might be caused by the decrease of HexA content in biotreated pulp (Table 2). That HexA $(240 \mathrm{~nm})$ was easier to be degraded to the UV-active compounds $(280 \mathrm{~nm})$ and then transformed to colored structures during light-induced yellowing, which is consistent with the previous research results $[42,43]$. F. concolor X4 treatment degraded HexA or changed HexA structures, thus blocking the transformation process of HexA to chromophores. Compared to the control, the decreases of $\nabla K / S$ around $340 \mathrm{~nm}$ for biotreated pulps (Figures 3(a) and 3(b)) suggested that less amounts of UVactive structures (aromatic carbonyl, etc.) could be generated after light-induced yellowing, which may from the degradation of aromatic-ring conjugated ethylenic bonds [44]. But the biotreatment using F. concolor X4 weakened the transformation process of these UV-active compounds (aromatic carbonyl, etc.) to chromophores (methoxyquinone, coniferyl aldehyde, o-quinone, etc.) during lightinduced yellowing $[5,45]$, thus leading to high stability of pulp brightness.

In the FTIR-ATR spectra of pulps, relative intensities of absorption bands related to hemicellulose were reduced, indicating that hemicellulose in pulp was degraded after F. concolor X4 treatment, which was also proved by the decrease of hemicellulose contents shown in Table 2. Absorptions belonging to aromatic skeleton had no obvious changes except for syringyl lignin, suggesting that just limit degradation occurred after $F$. concolor X4 treatment and aromatic structure was not effectively destroyed. Table 2 also shows that the lignin content was just slightly decreased after biotreatment. These changes in hemicellulose and lignin were conducive to the brightness stability of pulps.

\section{Conclusion}

Biotreatment of poplar CTMP using F. concolor X4 increased the pulp brightness and inhibited light-induced yellowing of the pulp. It was found that different types of enzymes such as Lip, MnP, xylanase, laccase, a small amount of cellulase, etc. were produced in pulp during the F. concolor $\mathrm{X} 4$ treatment. The enzymes could degrade part light-active components such as lignin, hemicellulose, and HexA or change some UV-active structures in lignin, which may be some reasons for brightness improvement and the brightness stability enhancement.

\section{Data Availability}

The data used to support the findings of this study are included within the article.

\section{Conflicts of Interest}

The authors declare that there are no conflicts of interest regarding the publication of this paper. 


\section{Acknowledgments}

This study was supported by the Natural Science Foundation of Shandong Province, China (ZR2019ZD19), National Natural Science Foundation of China (No. 31170107), and the Key Research and Development Project of Shandong Province, China (2019GSF107009 and 2019JZZY020223). The authors would like to thank Dr. Ye Yanxin, Dr. Du Jian, Dr. Lu Xianqin, and Dr. Wang Meimei for discussions on this manuscript.

\section{References}

[1] O. L. M. Kamoga, J. K. Byaruhanga, and J. B. Kirabira, "A review on pulp manufacture from non wood plant materials," International Journal of Chemical Engineering and Applications, vol. 4, no. 3, pp. 144-148, 2013.

[2] K. A. Deepika and P.S. Lal, "Melia dubia valorization at 4, 5and 6-year age for pulp and paper production," International Journal of Science and Research (IJSR), vol. 8, no. 2, pp. 613-623, 2019.

[3] O. L. Kamoga, J. Kirabira, J. Byaruhanga et al., "Characterisation and evaluation of pulp and paper from selected Ugandan grasses for paper industry," Cellulose Chemistry and Technology, vol. 50, no. 2, pp. 275-284, 2016.

[4] Y. Ni, Z. He, H. Zhang, and Y. Zhou, "Characteristics of high yield pulp and its effect on some typical wet-end issues," Journal of Biobased Materials and Bioenergy, vol. 5, no. 2, pp. 181-186, 2011.

[5] M. Paulsson and J. Parkås, "Light-induced yellowing of lignocellulosic pulps-mechanisms and preventive methods," BioResources, vol. 7, no. 4, pp. 5995-6040, 2012.

[6] N. A. Weir, J. Arct, and A. Ceccarelli, "Chromophore production in lignin model compounds-anaerobic reactions," Research on Chemical Intermediates, vol. 21, no. 3-5, pp. 353-371, 1995.

[7] U. P. Agarwal, J. D. Mcsweeny, and S. A. Ralph, "FT-Raman investigation of milled-wood lignins: softwood, hardwood, and chemically modified black spruce lignins," Journal of Wood Chemistry and Technology, vol. 31, no. 4, pp. 324-344, 1997.

[8] I. M. C. L. Sêco, C. P. Neto, and A. J. D. Silvestre, "Strategies to reduce the brightness reversion of industrial ECF bleachedEucalyptus globulus kraft pulp," Journal of Chemical Technology \& Biotechnology, vol. 83, no. 3, pp. 218-226, 2008.

[9] R. S. Davidson, L. Dunn, A. Castellan, and A. Nourmamode, "Attempts to photostabilize paper made from high-yield pulp by application of UV screens and control of $\mathrm{pH}$," Journal of Photochemistry and Photobiology A: Chemistry, vol. 86, no. 1-3, pp. 275-282, 1995.

[10] V. Trichet, S. Grelier, A. Castellan, H. Choudhury, and R. Stephen Davidson, "Attempt to photostabilize paper made from high-yield pulp by application of UV screens in conjunction with thiols," Journal of Photochemistry and Photobiology A: Chemistry, vol. 95, no. 2, pp. 181-188, 1996.

[11] R. Seltzer, J. P. Wolf, C. Heitner et al., "Inhibition of pulp and paper yellowing using nitroxides and other coadditives," 2000.

[12] M. E. Eugenio, S. M. Santos, J. M. Carbajo et al., "Kraft pulp biobleaching using an extracellular enzymatic fluid produced by Pycnoporus sanguineus," Bioresource Technology, vol. 101, no. 6, pp. 1866-1870, 2010.
[13] V. Gupta, S. Garg, N. Capalash, N. Gupta, and P. Sharma, "Production of thermo-alkali-stable laccase and xylanase by co-culturing of Bacillus sp. and B. halodurans for biobleaching of kraft pulp and deinking of waste paper," Bioprocess and Biosystems Engineering, vol. 38, no. 5, pp. 947-956, 2015.

[14] J. I. T. Sousa, A. I. G. Moura, D. V. Evtuguin et al., "Enzymatic treatment applied as a final stage in E. globulus kraft pulp bleaching," Journal of Chemical Technology \& Biotechnology, vol. 91, no. 22, pp. 547-554, 2015.

[15] A. Guerra, P. Pavan, and A. Ferraz, "Bleaching, brightness stability and chemical characteristics of Eucalyptus grandisbio-TMP pulps prepared on a biopulping pilot plant," in Proceedings of the 59th Appita Annual Conference and Exhibition: Incorporating the 13th ISWFPC (International Symposium on Wood, Fibre and Pulping Chemistry), Appita Inc., Auckland, New Zealand, May 2005.

[16] S. G. Nair, R. Sindhu, and S. Shashidhar, "Enzymatic bleaching of kraft pulp by xylanase from Aspergillus sydowii SBS 45," Indian Journal of Microbiology, vol. 50, no. 3, pp. 332-338, 2010.

[17] J. Ramos, T. Rojas, F. Navarro et al., "Enzymatic and fungal treatments on sugarcane bagasse for the production of mechanical pulps," Journal of Agricultural and Food Chemistry, vol. 52, no. 16, pp. 5057-5062, 2004.

[18] R. P. Chandra, J. N. Saddler, and R. P. Beatson, "Treatment of Douglas-fir heartwood thermomechanical pulp with laccases: effect of treatment conditions on peroxide bleaching," Journal of Wood Chemistry and Technology, vol. 27, no. 2, pp. 73-82, 2007.

[19] S. Tachibana, A. Nakano, K. Ohkub, and M. Sumimoto, "Studies on biological treatment of mechanical pulps iv: screening of wood-rotting fungi deressing light-induced color reversion of mechanical pulps," Japan Tappi Journal, vol. 46, no. 3, pp. 426-434, 1992.

[20] L. Li, X.-Z. Li, W.-Z. Tang, J. Zhao, and Y.-B. Qu, "Screening of a fungus capable of powerful and selective delignification on wheat straw," Letters in Applied Microbiology, vol. 47, no. 5, pp. $415-420,2008$.

[21] W. Tang, X. Li, J. Zhao, J. Yue, H. Yue, and Y. Qu, "Effect of microbial treatment on brightness and heat-induced brightness reversion of high-yield pulps," Journal of Chemical Technology \& Biotechnology, vol. 84, no. 11, pp. 1631-1641, 2009.

[22] M. Akhtar, "Biomechanical pulping of aspen wood chips with three strains ofCeriporiopsis subvermispora," Holzforschung, vol. 48, no. 3, pp. 199-202, 1994.

[23] J. Zhao, X. Li, and Y. Qu, "Application of enzymes in producing bleached pulp from wheat straw," Bioresource Technology, vol. 97, no. 13, pp. 1470-1476, 2006.

[24] H. Liao, S. Li, Z. Wei, Q. Shen, and Y. Xu, "Insights into highefficiency lignocellulolytic enzyme production by Penicillium oxalicum GZ-2 induced by a complex substrate," Biotechnology for Biofuels, vol. 7, no. 1, p. 162, 2014.

[25] A. Dhillon, J. K. Gupta, B. M. Jauhari, and S. Khanna, "A cellulase-poor, thermostable, alkalitolerant xylanase produced by Bacillus circulans $A B 16$ grown on rice straw and its application in biobleaching of eucalyptus pulp," Bioresource Technology, vol. 73, no. 3, pp. 273-277, 2000.

[26] M. L. Nikupaavola, E. Karhunen, P. Salola, and V. Raunio, "Ligninolytic enzymes of the white-rot fungus Phlebia radiata," Biochemical Journal, vol. 254, no. 3, pp. 877-883, 1988.

[27] A. G. Kumar, G. Sekaran, and S. Krishnamoorthy, "Solid state fermentation of Achras zapota lignocellulose by 
Phanerochaete chrysosporium," Bioresource Technology, vol. 97, no. 13, pp. 1521-1528, 2006.

[28] Y. Pu and A. J. Ragauskas, "Structural analysis of acetylated hardwood lignins and their photoyellowing properties," $\mathrm{Ca}$ nadian Journal of Chemistry, vol. 83, no. 12, pp. 2132-2139, 2005.

[29] C. Li and A. J. Ragauskas, "Brightness reversion of mechanical pulps. Part XVII: diffuse reflectance study on brightness stabilization by additives under various atmospheres," Cellulose, vol. 7, no. 4, pp. 369-385, 2000.

[30] S. Robert, C. Daneault, X. Pan, and A. J. Ragauskas, "Yellowing mechanism and kinetics of thick handsheets of softwood thermomechanical pulp," Journal of Wood Chemistry and Technology, vol. 15, no. 1, pp. 113-133, 1995.

[31] A. Sluiter, B. Hames, R. Ruiz et al., "Determination of structural carbohydrates and lignin in biomass," Laboratory Analytical Procedure, vol. 1617, no. 1, pp. 1-16, 2008.

[32] X. Chai, J. Zhu, and J. Li, "A simple and rapid method to determine hexeneuronic acid groups in chemical pulps," Journal of Pulp and Paper Science, vol. 27, no. 5, pp. 165-170, 2001.

[33] R. Rana, G. Müller, A. Naumann, and A. Polle, "FTIR spectroscopy in combination with principal component analysis or cluster analysis as a tool to distinguish beech (Fagus sylvatica L.) trees grown at different sites," Holzforschung, vol. 62, no. 5, pp. 530-538, 2008.

[34] B. Pizzo, E. Pecoraro, A. Alves, N. Macchioni, and J. C. Rodrigues, "Quantitative evaluation by attenuated total reflectance infrared (ATR-FTIR) spectroscopy of the chemical composition of decayed wood preserved in waterlogged conditions," Talanta, vol. 131, pp. 14-20, 2015.

[35] C. Zhou, W. Jiang, B. K. Via, O. Fasina, and G. Han, "Prediction of mixed hardwood lignin and carbohydrate content using ATR-FTIR and FT-NIR," Carbohydrate Polymers, vol. 121, pp. 336-341, 2015.

[36] S. Nie, S. Wang, C. Qin et al., "Removal of hexenuronic acid by xylanase to reduce adsorbable organic halides formation in chlorine dioxide bleaching of bagasse pulp," Bioresource Technology, vol. 196, pp. 413-417, 2015.

[37] A. K. Gangwar, N. T. Prakash, and R. Prakash, "Applicability of microbial xylanases in paper pulp bleaching: a review," BioResources, vol. 9, no. 2, pp. 3733-3754, 2014.

[38] M.-L. Mattinen, T. Suortti, R. Gosselink et al., "Polymerization of different lignins by laccase," BioResources, vol. 3, no. 2, pp. 549-565, 2008.

[39] I. F. Fiţigău, C. G. Boeriu, and F. Peter, "Oxidative polymerization of lignins by laccase in water-acetone mixture," Acta Biochimica Polonica, vol. 60, no. 4, pp. 817-822, 1970.

[40] E. Woolridge, "Mixed enzyme systems for delignification of lignocellulosic biomass," Catalysts, vol. 4, no. 1, pp. 1-35, 2014.

[41] L. Jianxiang, W. Jinquan, M. Yongwen et al., "Influence of laccase/glutamic acid system on structure and properties of old corrugated containers fiber," Chemistry and Industry of Forest Products, vol. 37, no. 3, pp. 67-72, 2017.

[42] O. Sevastyanova, On the Importance of Oxidizable Structures in Bleached Kraft Pulps, KTH Royal Institute of Technology, Stockholm, Sweden, 2005.

[43] D. Zhang, X. Li, M. Wang et al., "Xylanase treatment suppresses light- and heat-induced yellowing of pulp," Scientific Reports, vol. 6, p. 38374, 2016.

[44] A. Karlsson, S. Enberg, M. Rundlöf, M. Paulsson, and P. Edström, "Determining optical properties of mechanical pulps," Nordic Pulp \& Paper Research Journal, vol. 27, no. 3, pp. 531-541, 2012.
[45] J. Keating, C. I. Johansson, J. N. Saddler, and R. P. Beatson, "The nature of chromophores in high-extractives mechanical pulps: western red cedar (Thuja plicata Donn) chemithermomechanical pulp (CTMP)," Holzforschung, vol. 60, no. 4 , pp. 365-371, 2006. 